\title{
Design of Servo Control System on CNC Spinning Machine
}

\author{
Peng Shen and Yulong Zhang \\ University of Science and Technology Liaoning, China \\ sp-1981@163.com,48470157@qq.com
}

\begin{abstract}
The abstract is the technology of spinning has developed for more than 40 years. Especially in recent years, contributed a lot to Chinese equipment manufacturing industry and various kinds of spinning equipment have been developed, but it is blank in the light industry and civil industry. Due to the high cost and programming complexity of NC machine tools, we have no dedicated spinning machine and mostly rely on simple manual in the lampcover production. As to the above problems, we developed the lampcover NC spinning machines that can generate the track automatically and complete automatic control in the machining process.
\end{abstract}

Key words: Lampcover, CNC spinning, Servo control system

\section{Introduction}

Spinning process, exerted pressure to the rough material with spinning tools, produced a continuous local plastic deformation and molded into the desired hollow rotary parts. Spinning process, which is commonly used process method, manufactured the thin-walled revolution workpieces and completed many different forming processes, such as, drawing, flanging, hemming etc. Spinning technology has promoted cutting-edge technology development of the aircrafts, rockets, missiles and satellites. Also it has been widely used in the chemical industry, metallurgy, machinery manufacturing, light industry and civil industry. As a new technology, spinning processing has formed a new field in modern metal pressure processing. Spinning is a kind of new chipless processing technology in the field of metalworking. The Spinning processing, which utilized the metal's ductility and combined the chracteristics of forging, extruding, drawing, bending, ring rolling and cross rolling, realizes no cutting processing quality and high efficiency of metal forming process.

Because the lampcover spinning die has the advantage of low cost and convenient processing, the production of the lampcover, which is frequently shape-changing and produced in small batch, has changed the process from a stamping process to a spinning one. As the product is smaller and changes size, the process often need change its processing track. Also, as the workpiece's dimension is different and workpiece processing parameters are not the same, there was no fixed rule. So we need to develop specialized NC system of processing lampcover spinning machine.

\section{Overall Design of the Lampcover NC Spinning Machine}

There are two written forms of software's control program, The NC system of lampcover spinning machine that we are using now is secondary developed by standard CNC system: One is manually drawn CAD tool track diagram, calculating $\mathrm{X}, \mathrm{Z}$ interpolation position and finally writing the G-code program; the other is CAD drawing deformation curve, using a dedicated compiler software and compiling tool track curves into a G-code program [1]. But in fact most functions of CNC system are not suitable for the lampcover NC spinning machines. Since the workpiece's size varies, we need change 
CAD deformation curve in the above two forms and change the code, not only increasing the processing cost, but also reucing production efficiency. So the use of standard NC system is not perfect [2].

According to the above reasons, we developed NC system of lampcover spinning machine. It needs to input die parameters, processing track parameters and lamp processing parameter, then generates tool-track in accordance with algorithm automatically, and hob works according to the locus contour of spinning processing. If the result is not ideal, we can input the processing parameters again and the system can generate a new track diagram. Thus, it saves programming process and improves the production efficiency. Lampcover NC spinning machine is mainly composed of two major components: the mechanical system [3-5] and the electrical control system. The mechanical system mainly includes hob rack system, in which the servo motor and holder are connected by the ball screw, realizing position control; the die system is the one in which the spindle motor, lampcover die are connected and the die and the motor rotate synchronously; the end top clamping system finishes the spinning process by clamping the workpiece, synchronous rotation of the spindle and the workpiece, and repeated driving pressure by the hob. Mechanical system of lampcover spinning machine is shown in Figure 1.

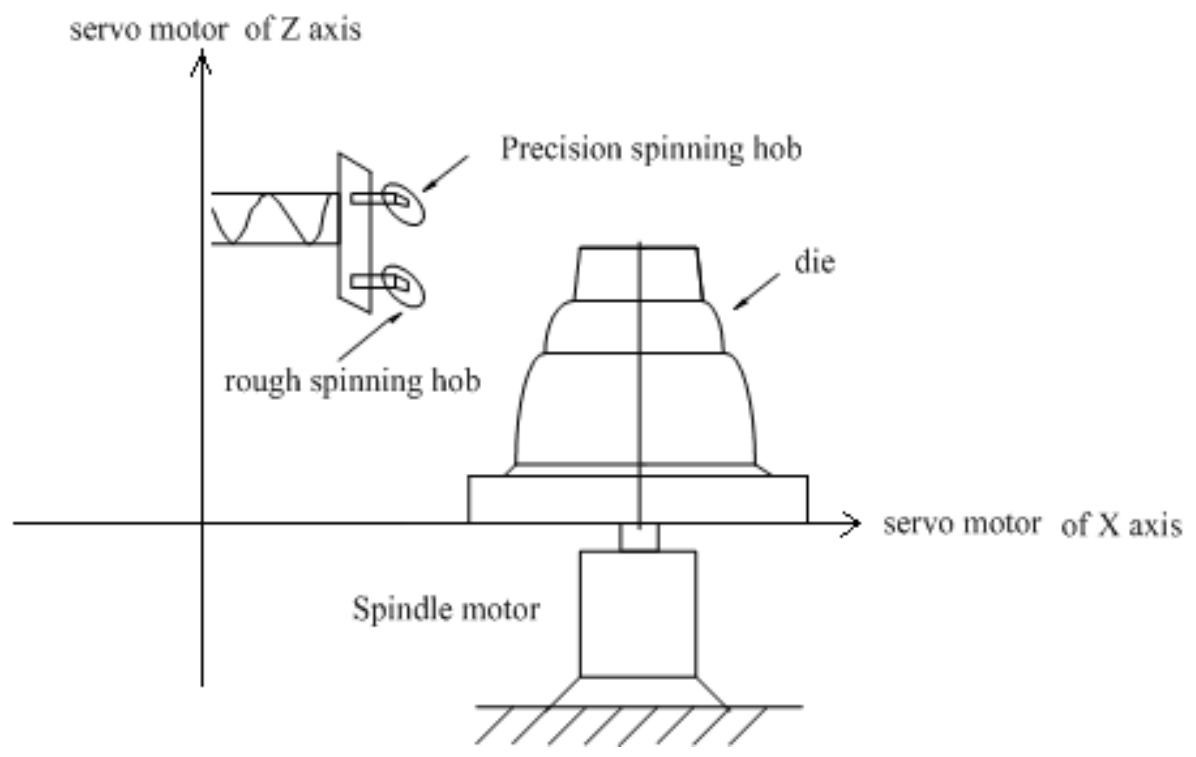

Figure 1. Mechanical System of Lampcover Spinning Machine

\section{Design of Control System of the Lampcover NC Spinning Machine}

Processing track contour parameters: the starting point of outer contour and the terminal point of outer contour.

Lampcover processing parameters: the total number of tool time, the processing initial angle, the diameter of precise spinning hob, the diameter of rough spinning hob, the number of waving tool and the speed of hob travel.

According to the technological requirement, the following die parameters are input: total sections of the die's shape track, the type of each shape track (linear / circular arc), the starting point and terminal point of each shape track and the arc track radius of each section; so the system generates the lampcover contour graph.

According to the input parameters, the specialized numerical control system generates automatically the hob traveling track diagrams as shown in Figure 2 [6-7]. 


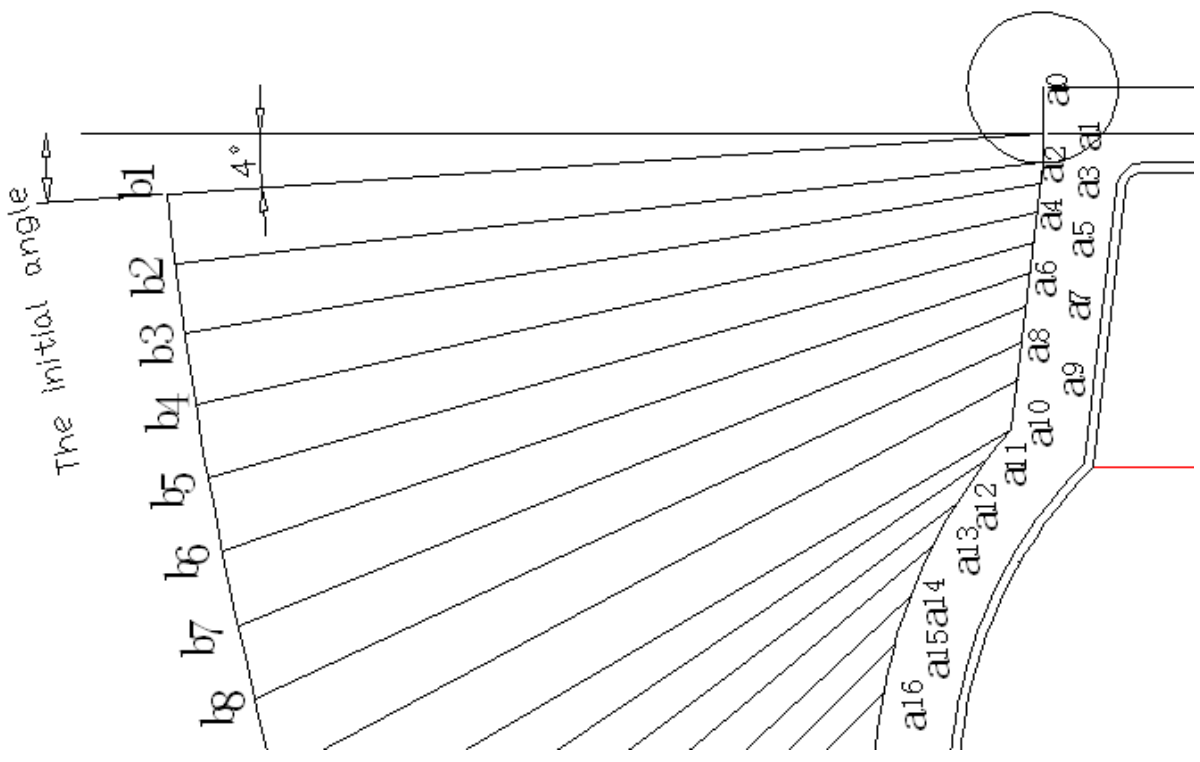

Figure 2. Hob Processing Track Diagrams of the Lampcover NC Spinning Machine

Spinning tracks toolpath generation algorithm:

(1). total knife ones external input, the total length $\mathrm{L}$ is part height minus the sheet thickness.

(2). To establish a stable processing surface in the $\mathrm{Z}$ direction feed amount of the first blade $30 \% \mathrm{k} 1$ times the diameter of the wheel,

Where: $\mathrm{k} 1=0.2 \sim 2$ The default value is $1, \mathrm{k} 1$ value by the external input

(3). $\mathrm{Z}$ direction of the rest of the knife times the amount of feed mode using arithmetic sequence:

First a1 $=0.5 \mathrm{k} 2 \mathrm{Sn} /(\mathrm{n}-1)$, where $\mathrm{n}$ : total knife ones; k2 $=0.2 \sim 2$ default is 1 , k2 value by the external input Such difference $d=2(\operatorname{Sn}-(\mathrm{n}-1)$ a1 $) /((\mathrm{n}-1)(\mathrm{n}-2))$

Assuming: $\mathrm{n}=28$, hob diameter $\mathrm{D}=16 \mathrm{~mm}$, thickness $1 \mathrm{~mm}$ Measuring the height chart on the part of: $145 \mathrm{~mm}$ Can be obtained: $\mathrm{L}=145-1=144 \mathrm{~mm}$,

$\mathrm{Sn}=144-0.3 \times 16=139.200 \mathrm{~mm} \quad \mathrm{a} 1=2.578 \mathrm{~mm}, \mathrm{~d}=0.198 \mathrm{~mm}($ after the decimal point three)

And then find the amount of feed (unit:mm) each pass is:

\begin{tabular}{|l|l|l|l|l|l|l|l|}
\hline Passes & 1 & 2 & 3 & 4 & 5 & 6 & 7 \\
\hline $\begin{array}{l}\text { Reduction } \\
\text { degree }\end{array}$ & 4.800 & 2.578 & 2.776 & 2.975 & 3.173 & 3.371 & 3.569 \\
\hline Passes & 8 & 9 & 10 & 11 & 12 & 13 & 14 \\
\hline $\begin{array}{l}\text { Reduction } \\
\text { degree }\end{array}$ & 3.768 & 3.966 & 4.164 & 4.363 & 4.561 & 4.759 & 4.957 \\
\hline Passes & 15 & 16 & 17 & 18 & 19 & 20 & 21 \\
\hline $\begin{array}{l}\text { Reduction } \\
\text { degree }\end{array}$ & 5.156 & 5.354 & 5.552 & 5.751 & 5.949 & 6.147 & 6.346 \\
\hline Passes & 22 & 23 & 24 & 25 & 26 & 27 & 28 \\
\hline $\begin{array}{l}\text { Reduction } \\
\text { degree }\end{array}$ & 6.544 & 6.742 & 6.940 & 7.138 & 7.337 & 7.535 & 7.734 \\
\hline
\end{tabular}

(4). Z parameter setting the initial point of the center track is " 0 ", the corresponding parameters on the center track points each pass can seek $\mathrm{Z}$

The diameter of the $\mathrm{X}$ parameter is the appropriate point.

(5). initial angle spinning external input, end angle, without interfering with the premise contour $45^{\circ}$, if the contour 
Interference in accordance with the outline whichever angle, channel level attained before the second pass spinning angle increases $3^{\circ}$ :

The first blade angle: external input angle.

The second blade angle: external input angle plus $3{ }^{\circ}$.

The third angle of the knife: The second knife angle plus $3{ }^{\circ}$.

So the spinning angle reaches $45^{\circ}$, after each pass in accordance with $45^{\circ}$ angle.

(6). From the center of the track in turn crossed each pass node according to the angle and the "foreign minister intersection arc trajectory" of each intersection point $b$,

Road is the outer edge of the knife point, calculate the coordinates of the corresponding $\mathrm{X} / \mathrm{Z}$ parameters.

(7). determines the arc intersects the outer track: over the workpiece material and the outermost point of the head draw an arc, the arc radius of 1.5 times the diameter of the raw material

Multiplied by the coefficient $\mathrm{k} 3$, where: $\mathrm{k} 3=0.5 \sim 2$ default value is $1, \mathrm{k} 3$ value by the external input

By using the known starting point $\mathrm{a}$, terminal point $\mathrm{b}$ and reduction degree $\mathrm{h}$, we can get the radius of arc track. Sending the calculated track into the servo system, the system can reach the control accuracy and instantaneity of processing track in accordance with the requirements [8].

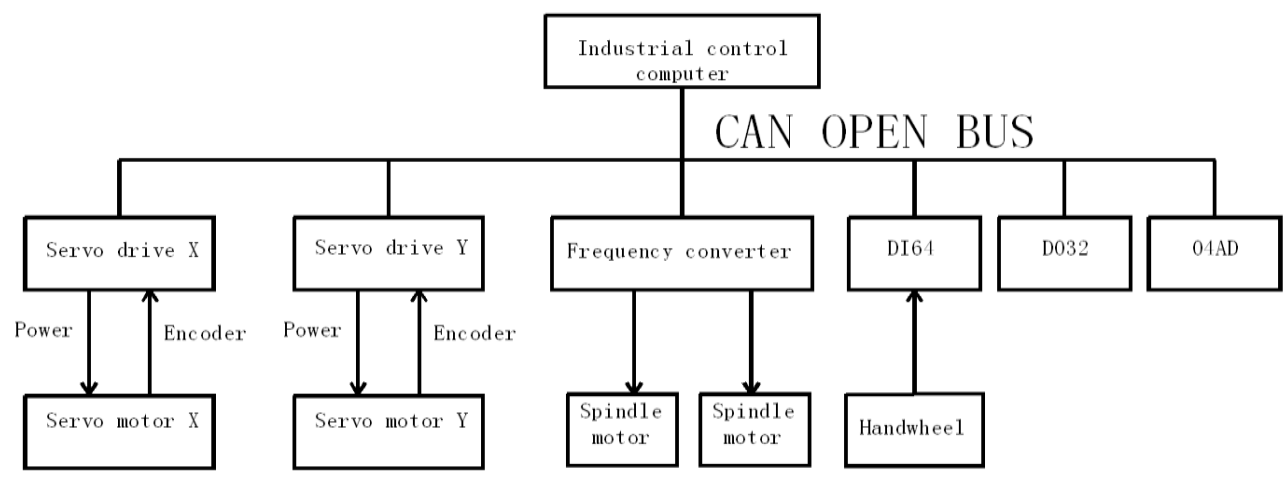

Figure 3. Control System of Lampcover Spinning Machine

The RM64MN, switching value input module, loaded in the industrial machine, completes the inputting and acquiring work of external machine proximity switch signal, monitoring instantly whether the hob position is beyond the trip or not. The RM32NT, switching value output module, mainly completes the automatic control of the machine's armswinging, clamping, pneumatic switch valve's hob switching. So the control system can realize the fully automated production of the lampcover, in the course of which first we can make material preparation and later hob spinning process sequentially.

Processing operation system, which is mainly composed of Industrial control computer system, is shown in Fig.3. First, input the die parameters, outer contour parameters and lampcover processing parameters into the spinning operation software written by industrial control computer, complete the lampcover processing operation setting; thus the system generates the spinning track automatically according to the track algorithm. Then, adopt the curve interpolation and decompose processing track to $\mathrm{X}$ axis and $\mathrm{Z}$ axis, and the interpolation values were calculated as position given values of $X$ axis servo drive and $\mathrm{Z}$ axis servo drive; so the two servo motors can coordinate and complete the spinning processing track[9].

The output frequency of spindle frequency converter needs real-time adjustment when spinning track in different stages and spinning different workpieces. It can upload the real-time position information and spindle speed information into the industrial control 
computer system by the bus connection. According to the feedback information, computer operating system sends the control commands of accurate position and inverter speed, completeing accurate machining processing.

Servo drive system, according to the track command issued by Industrial control computer, completes the automatic control of processing tracks of $\mathrm{X}$ and $\mathrm{Z}$ axis servo motor. Servo system control principle is shown in Figure 4. Current control unit outputs three-phase current modulation wave, through pulse signal output by PWM, to control IGBT and realize the current control, and finally reach the goal of position control [10].

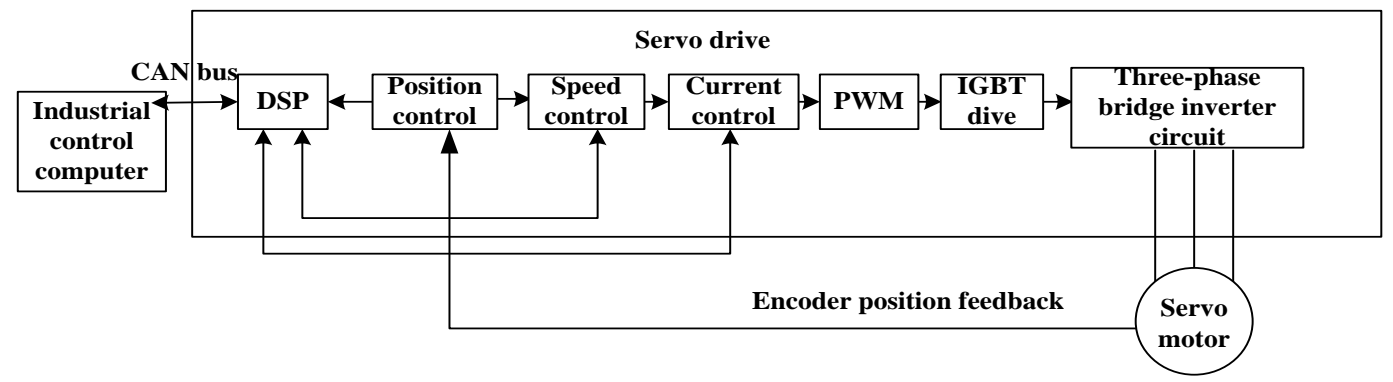

Figure 4. Servo System Control Principle

Machine tool equipment system, consists of bed's servo motor and spindle motor, completes the transmission control of the machine tool table and the die system [11-12].

\section{Analysis on the Test Results of the Numerical Control System}

Servo motor speed waveform and current waveform are shown in Figure 6 and Figure 7. In the course of tests on lampcover specialized CNC system and spinning machine, the spinning machine can process a finished piece within 3 minutes and machining accuracy can be achieved $\pm 0.01 \mathrm{~mm}$. The response of positive and negative transition process of servo system is quick, and it can complete the conversion from top speed of positive rotation to top speed of negative rotation in $200 \mathrm{~ms}$. The current was adjusted a bit in about $100 \%$ rated current when the loading system operates at high speed. Each time the spinning system extrudes the workpiece at high speed, the speed stability can be guranteed by the current adjustment.

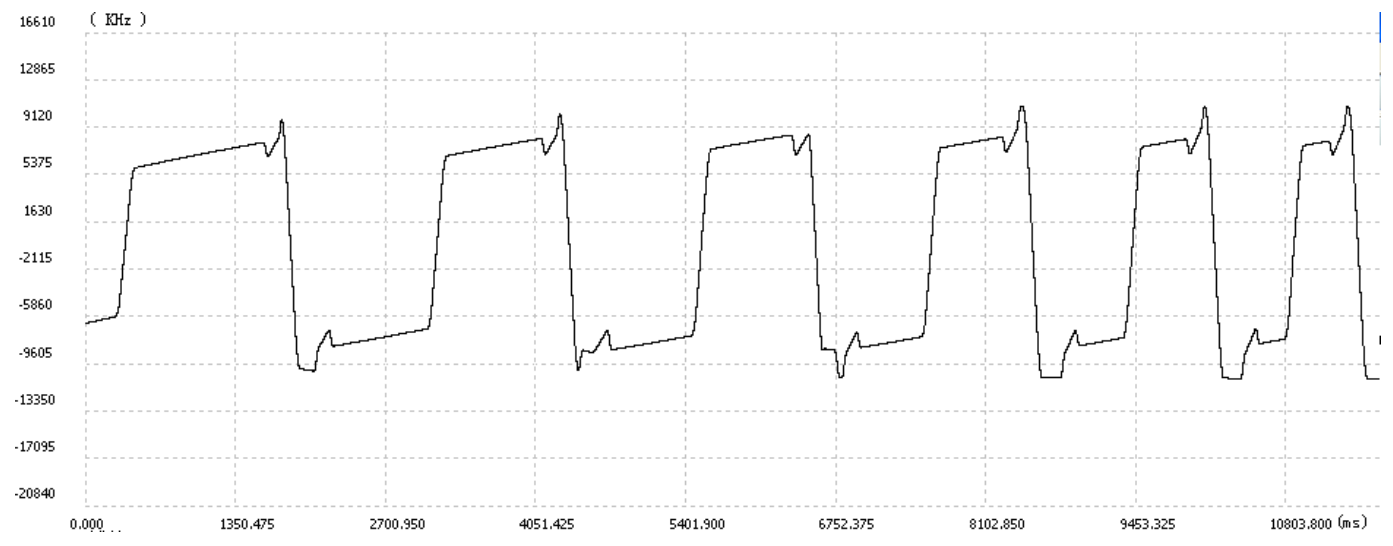

Figure 6. Servo Motor Speed Waveform 


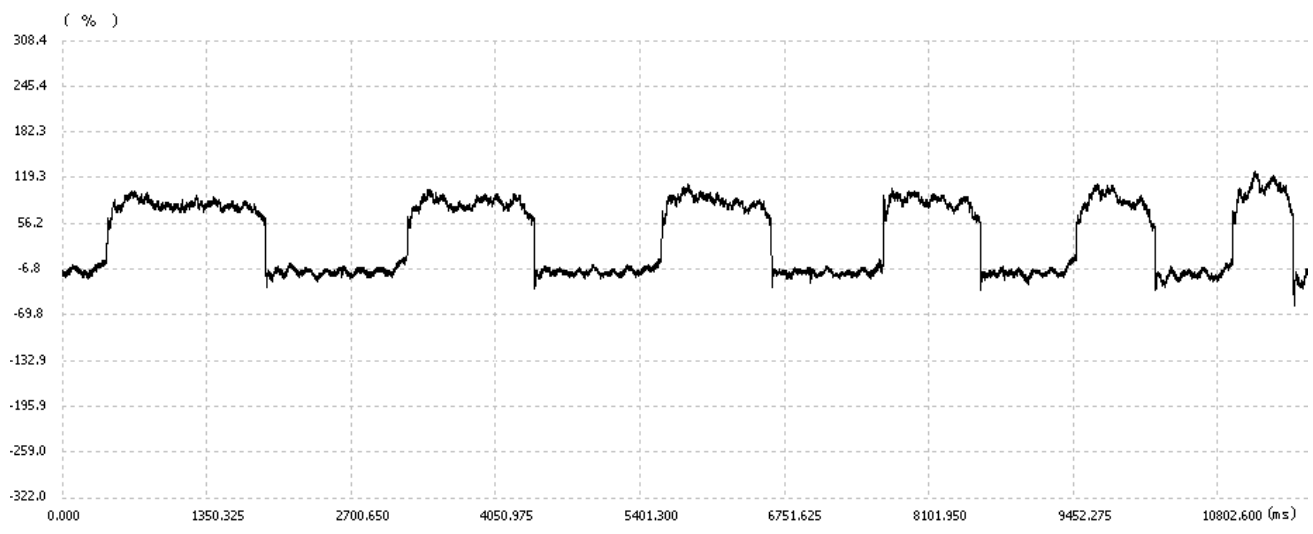

Figure 7. Servo Motor Current Waveform

\section{Programming}

Figure 8 is the diagram of the system program. As shown in the figure, it is necessary to determine whether the data is reasonable first based on the actual scope of work machine. The program can be divided into four steps: (1) find the equidistance line for each curve segment; (2) determine whether there exist intersection between two adjacent equidistance lines, thus determine whether need to add tweened transition arc and mark whether it is valid or not; (3) remove all invalid equidistance curves and tweened transition arcs; (4) reorganize the remaining equidistance curves. The key point is the step 3.

The sub-program of removing invalid tweened transition arc is shown in diagram in Figure 9, which is the core of our algorithm. First, we find an invalid tweened transition arc, then mark two valid equidistance curves which are before and after it. For easy description, we term the before one as Fore-cure, and the after one as Post-curve. Then, we determine whether there exists intersection between the two curves (intersection must on two curves, not on their extended lines). If they intersect, the intersection is used directly to redraw equidistance curves, and it is regarded as the end point of the Fore-curve and the start point of the Post-curve. Then, delete invalid tweened transition arcs. If they do not intersect, we need to determine the position relation between the Fore-cure and Post-curve. In normal case, if the start point of the Post-curve is smaller than the end point of the Fore-curve, the Post-curve is considered as invalid. Then, we delete invalid tweened transition arcs and the Post-curve and proceed to find other invalid tweeded transition arcs. 


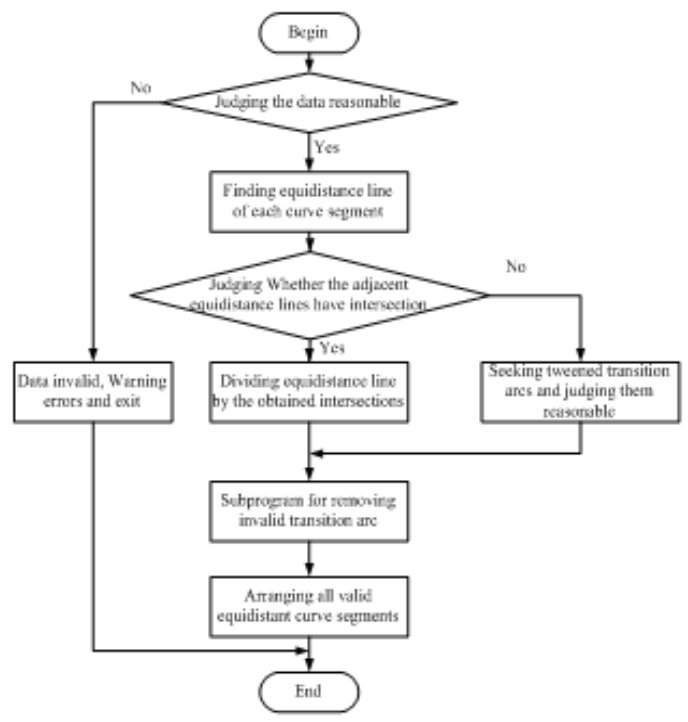

Figure 8. Algorithm Flow Chart

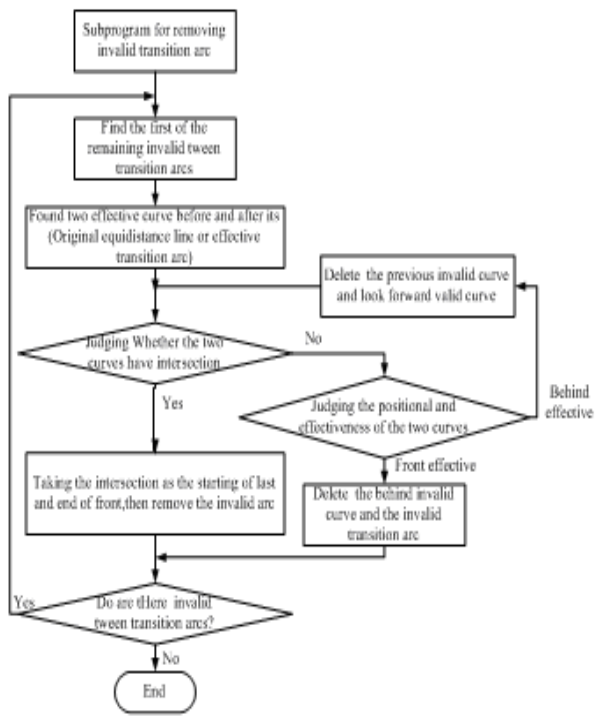

Figure 9. Subprogram for Removing Invalid Transition Arc

Figure 10 describes two mold processing tool paths in practical applications. The curves which are marked "Contour" at the bottom are actual contour curves of mold. Its main characteristic parameters includes: (1) the number of segments in the curves combination; (2) the start and end point of each segment; (3) the type of segment; (4) the radius and the direction of arc if the segment is arc. The middle curves which are marked "r=5mm" are the trajectory of precision rotary knife with radius $5 \mathrm{~mm}$. The curves which are marked " $\mathrm{r}=8 \mathrm{~mm}$ " are generated trajectory of coarse rotary knife with radius $8 \mathrm{~mm}$. Here, the radius is the equidistance $d$ in finding the equidistance curves. The extending curves are transition curves machining process.

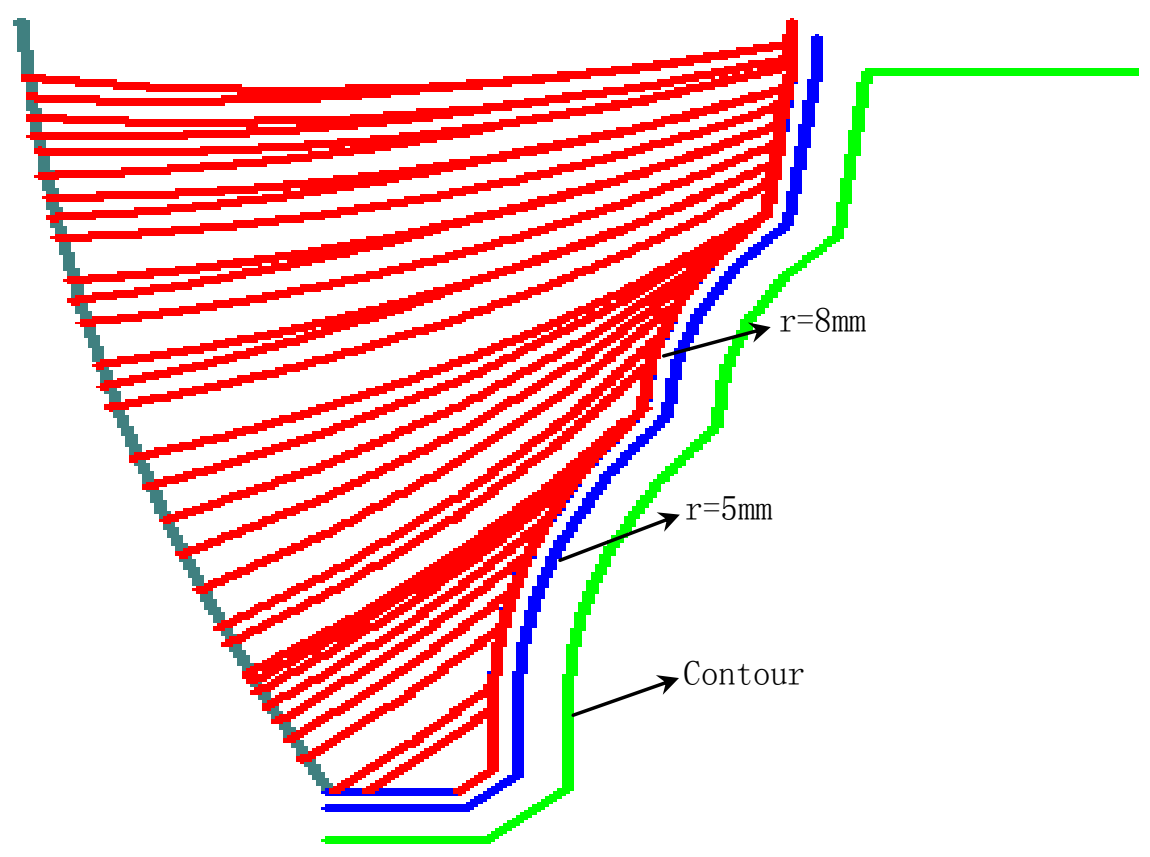

Figure 10. The Actual Processing Locus 


\section{Conclusion}

Because the lampcover's shape and size are changeable, and there are hundreds of processing dies, we only tested ten kinds of typical lampcovers among them. After the die and processing parameters are input, the specialized NC system can generate lampcover spinning processing track accurately and automatically. After being tested in prodution and processing for a long time, the software system keeps stable without crashes or malfunction.

By studying the NC system of lampcover spinning machine, we filled in the blank in the NC spinning machine applying in the lighting industry, and realized the control algorithm and the control system of automatic generation of spinning track.

\section{References}

[1] J. Jin and Q. Shao, "Automatic Programming and Simulation for NC Spin Forming Based on AutoCAD [J]”, Mechatronics, vol. 2, (2006), pp. 63-65.

[2] Y. Han, "Spinning machine automatically connect solutions [J]", Electric Engineering, vol. 7, (2009), pp. 45-46.

[3] X. Yin, "TH6940 column and drag the spindle box design [A]", Scientific development and social responsibility, vol. A, (2008), pp. 145-150.

[4] Y. Wang, C. Lin and J. Li, "Research of Vertical Power Spinning Machine [J]", Aeronautical Manufacturing Technology, vol. 17, (2011), pp. 62-65.

[5] G. Ge, F. Yang and X. Zhang, "Electric Screw Press Driven by Switched Reluctance Motor [J]", Electric Machines \& Control Application, vol. 39, (2012), pp. 11-15.

[6] J. Yang, Z. Xu and J. Zhou, "The Study of Automation Programming System for NC Spinning Machine Based on DXF File [J]", JOURNAL OF SHANGHAI ELECTRIC TECHNOLOGY, vol. 4, (2011), pp. 15-19.

[7] X. Cheng, Y. Wang and Q. Xia, "Development of the Application Software Based on ARM Embed System of CNC Spinning Machine [J]”, JOURNAL OF COMPUTER APPLICATIONS, vol. 3, (2008), pp. 90-93.

[8] Y. Zeng, X. Zeng and C. Bai, "Research on Aoutomatic Pressure of Two Verticil Profile Modeling Rotating and Pressing Automatic Machine Tool [J]", Machine Tool \& Hydraulics, vol. 6, (2003), pp. 193-195.

[9] Y. Dong, "The Development of the Power Spinning Machine Based on Old Lathe [J]", Development \& Innovation of Machinery \& Electrical Products, vol.7, (2008), pp. 191-194.

[10] S. Fang and J. Zhang, "Development of automatic vertical machine of spinning [J]", Machinery Design \& Manufacture, vol. 2, (2007), pp. 22-23.

[11] K. N. Vijeyakumar, V. Sumathy, E. J. Aishwarya, S. Saravanakumar, M. Gayathri Devi, "VLSI Architecture for Low Power Minimum Signed Digit Multiplier for fir Filter and ITS Signal Processing Applications [J]", Journal of Theoretical and Applied Information Technology, vol. 42, (2012), pp. 050 058 .

[12] Z. Liu, L. Zhao and Z. Bian, "ERROR MODELING FOR STRUCTURAL DEFORMATIONS OF MULTI-AXIS SYSTEM BASED ON SVR [J]", Journal of Theoretical and Applied Information Technology, vol. 47, (2013), pp. 1058 - 1065. 